\title{
Flat roof surface temperature assessment using IRT
}

\author{
by N. Simões*,** , C. Serra*,** and I. Simões ${ }^{*, * *}$ \\ * ITeCons - Institute for Research and Technological Development for Construction, Energy, Environment and \\ Sustainability, Rua Pedro Hispano s/ n., 3030-289 Coimbra, Portugal, nasimoes@itecons.uc.pt \\ **ADAI - LAETA, Department of Civil Engineering, University of Coimbra, Pólo II, Rua Luís Reis Santos, 3030- \\ 788 Coimbra, Portugal
}

\begin{abstract}
The use of green roofs in buildings is becoming more popular as people become more aware of the effects of human activities on the environment, and of the growing need for implementing climate change adaptation and mitigation solutions. Amongst the many known benefits associated with green roofs, is the potential to reduce surface temperature. This is particularly important in urban areas and in warmer climates.

This work aims to contribute to the study of evaluating the effect of installing green roof technology, via the implementation of an Infrared thermography technique to assess flat roof surface temperature.
\end{abstract}

\section{Introduction}

Growing concerns with climate change and the scarcity of resources have been motivating research and development in many areas all around the world to come up with concrete actions to minimize the negative effects of human activities on the environment [1]. In particular, one of the many consequences of urbanization is a phenomenon known as the urban heat island effect (UHI). This refers to the fact that, in recent years, many urban areas have been consistently recording higher temperatures than compared to their surrounding rural areas, particularly during the summer months. UHI is believed to happen in great part due to the loss of green spaces and the consequent loss of shading and evaporative cooling granted by the vegetation. Additionally, because of their density of population and infrastructure, urban areas are responsible for a great percentage of energy-related emissions of greenhouse gases. As the urbanization trend continues and people are becoming increasingly aware of these problems, pressure is being put on policy makers, researchers and industry to come up with solutions. However, the development of new conventional green spaces is often not economically viable due to the high land value in urban areas. This has given way to an increase in the implementation of green roofs and façades in buildings [2].

Green roofs are known to present many benefits, which have been thoroughly documented in the literature, such as in [3] and [4]. Among those benefits, green roofs contribute to the minimization of the UHI effect [5] via both the evapotranspiration of plants and soil, which helps cool the air, and also because their implementation can reduce reflection when compared to conventional surfaces. Some studies looking to assess the effects of implementing green roofs [6] and cool roofs [7] can already be found, however, their findings are limited, since results will greatly vary according to the different climates, types of solutions (species of plants in green roofs or reflective material in cool roofs) and types of approaches (experimental analysis vs. use of simulation models).

The work presented in this paper aims to contribute to this discussion by focusing on the implementation of an infrared thermography (IRT) technique for the assessment of surface temperature in several solutions, including green roofs. The goal is to evaluate the energy emitted by flat roofs using different coating systems under specific conditions.

\section{Methodology}

In this study, an experimental IRT technique is proposed and implemented, looking to assess the surface temperature of different flat roof solutions such as: conventional coating with ceramic tiles, inverted ballasted roof, green roofs (with different plant species), brown roofs, medium density expanded cork board coating system.

The specimens are kept in specific laboratorial conditions and subjected to artificial thermal stimulation from halogen lamps. Additional parameters are also considered, such as the influence of the varying water content and changing plant species (in green roofs). Thermal images are recorded over time, and the results for the different solutions are compared and interpreted. Furthermore, the influence of changing the duration of the heating period is analysed in order to better define experimental parameters.

\section{Acknowledgements}

This work was framed within the POCI-01-0247-FEDER-017844 (GreenSolarShade) Project funded by Portugal 2020 through the COMPETE 2020. 


\section{REFERENCES}

[1] IPCC, Climate Change 2014: Synthesis Report. Contribution of Working Groups I, II and III to the Fifth Assessment Report of the Intergovernmental Panel on Climate Change [Core Writing Team, R.K. Pachauri and L.A. Meyer (eds.)]. IPCC, Geneva, Switzerland.

[2] White R. Building the Ecological City. Woodhead Publication, Cambridge. 2002.

[3] Berardi U, GhaffarianHoseini A, GhaffarianHoseini A. State-of-the-art analysis of the environmental benefits of green roofs, Applied Energy 2014;115:411-428.

[4] Vijayaraghavan K. Greenroofs: A critical review on the role of components, benefits, limitations and trends, Renewable and Sustainable Energy Reviews 2016;57:740-752.

[5] Lehmann S. Low carbon districts: Mitigating the urban heat Island with green roof infrastructure. City, Culture and Society 2014;5:1-8.

[6] Razzaghmanesh M, Beecham S, Salemi T. The role of green roofs in mitigating Urban Heat Island effects in the metropolitan area of Adelaide, South Australia. Urban Forestry \& Urban Greening 2016;15:89-102.

[7] Al-Obaidin K, Ismail M, Rahman A. Passive cooling techniques through reflective and radiative roofs in tropical houses in Southeast Asia: A literature review. Frontiers of Architectural Research 2014;3:283-297. 